Article

\title{
Transcending the Suffering in Cancer: Impact of a Spiritual Life Review Intervention on Spiritual Re-Evaluation, Spiritual Growth and Psycho-Spiritual Wellbeing
}

\author{
Lenneke Post $1,2, *\left(\mathbb{D}\right.$, R. Ruard Ganzevoort ${ }^{2}$ and Irma M. Verdonck-de Leeuw ${ }^{3,4}$ \\ 1 Department of Spiritual Care, Amsterdam UMC, Vrije Universiteit Amsterdam, De Boelelaan 1117, 1118, \\ 1081 HV Amsterdam, The Netherlands \\ 2 Faculty of Religion and Theology, Vrije Universiteit Amsterdam, De Boelelaan 1117, 1118, \\ 1081 HV Amsterdam, The Netherlands; r.r.ganzevoort@vu.nl \\ 3 Department of Otolaryngology - Head \& Neck Surgery, Amsterdam UMC, Vrije Universiteit Amsterdam, \\ De Boelelaan 1117, 1118, 1081 HV Amsterdam, The Netherlands; im.verdonck@amsterdamumc.nl \\ 4 Faculty of Behavioural and Movement Sciences, Department of Clinical, Neuro- \& Developmental \\ Psychology, Vrije Universiteit Amsterdam, De Boelelaan 1117, 1118, 1081 HV Amsterdam, The Netherlands \\ * Correspondence: h.post@amsterdamumc.nl
}

Received: 18 February 2020; Accepted: 15 March 2020; Published: 20 March 2020

\begin{abstract}
In the confrontation with cancer, spiritual re-evaluation may help people to transform all-encompassing suffering into spiritual growth and psycho-spiritual wellbeing. The aim of this study was to examine whether spiritual life review (SLR), a semi-structured group narrative intervention that supports people with cancer to write and present their spiritual life story, is effective for the improvement of spiritual re-evaluation, spiritual growth, and psycho-spiritual wellbeing. In this mixed methods study, 57 cancer patients participated. Quantitative data were collected by means of patient reported outcomes (SAIL, Dutch Ryff, and NEIS) at baseline, post-intervention, and three and nine months follow-up (44 participants completed up to 9 months post-intervention). Changes over time were assessed via linear mixed model analysis (LMM). Qualitative data were collected by means of semi-structured interviews with 33 participants nine months post-intervention, and were coded in a two-stage process. Participating in SLR facilitated spiritual re-evaluation, and improved the course of spiritual growth, psycho-spiritual wellbeing, and ego-integrity. This study provides evidence that SLR is likely to improve spiritual re-evaluation, spiritual growth, and psycho-spiritual wellbeing after confrontation with cancer; it also suggests the importance of self-affirmation and ego-integrity for spirituality; and underscores the relevance of narrative spiritual interventions in the oncology setting.
\end{abstract}

Keywords: cancer; spiritual re-evaluation; existential re-evaluation; narrative interventions; spiritual autobiography; spiritual life story; spiritual growth; spiritual wellbeing; ego-integrity

\section{Introduction}

A cancer diagnosis radically confronts people with the limits of existence. Life, people with cancer experience firsthand, is uncertain and cannot be controlled fully, while people are mortal, vulnerable, and dependent upon each other and the unknowable. Paradoxically, although the confrontation with cancer thus disrupts and pervades one's entire life and may lead to existential despair, and an all-encompassing suffering, characterized by the experience of alienation, helplessness, hopelessness, and meaninglessness, this confrontation might also lead to powerful processes of transcendence and transformation, prompting a new awareness of the body, an existential re-evaluation and reappraisal 
of life, development of the self, and a sense of personal and spiritual growth, connectedness, and inner peace (Best et al. 2015; Hefferon et al. 2009; Kissane 2012; Vehling and Kissane 2018).

But how? How can a confrontation with a life-threatening illness such as cancer lead to both suffering and transcendence? How can all-encompassing suffering be turned into personal and spiritual growth, connectedness and inner peace? Moreover, how can we facilitate this transformation? Based on a conceptual review spanning twenty years of empirical psychological research, Best et al. (2015) suggest that transcendence of the suffering in cancer is attained by means of personal and spiritual growth, as one - through re-evaluation of oneself-finds new meaning and priorities; lives one's life and relationships accordingly; and experiences wellbeing, peace, and inner harmony. They consequently propose that the assessment, care, and treatment of suffering in cancer requires engagement with the spiritual health and spirituality of the sufferer; and thus engagement with the manner in which people find meaning and purpose, and experience their connectedness to the self, others, and the significant, or sacred. Recent meta-analyses investigating the efficacy of spiritual and existential interventions for people with cancer similarly suggest that spiritual interventions may improve psycho-spiritual well-being and quality of life (Bauereiß et al. 2018; Oh and Kim 2014; Park et al. 2015; Xing et al. 2018). However, these meta-analyses also show that the components of these interventions are very diverse, necessitating further (theoretical and empirical) research into the efficacy of different components of spiritual interventions, so as to design more theoretically based and reliable implementation methods (Bauereiß et al. 2018; Xing et al. 2018).

The aim of this study is to further our understanding of the mechanism and impact of spiritual re-evaluation in the context of cancer, and explore the role a narrative spiritual intervention might play in this. Our focus is particularly on understanding how a spiritual narrative intervention aimed at evaluating one's life and oneself in light of one's ultimate concern, might facilitate spiritual re-evaluation, and to what extent this intervention impacts spiritual growth and psycho-spiritual well-being. In the following, we first develop a theoretical model to understand the dynamics of spiritual re-evaluation in the face of cancer. We consequently explore the role spiritual life review intervention might play in this. We then present our mixed methods empirical research on the impact of a spiritual life review (SLR), a semi-structured group intervention aimed at the reflection on, and writing and presentation of, one's spiritual autobiography.

\subsection{Cancer as a Limit Situation: Existential Despair, Spiritual Re-Evaluation, and Self-Transcendence}

The confrontation with cancer can be conceptualized as a limit situation, as a radical disruption of life that not only urgently makes one aware of the limits of the self, but also ignites the human desire and ability to enhance life, and transcend the limits to concrete finite existence (Anbeek 2013; ter Borg 2010; Jaspers 1919, 1938, 1951; Taylor 2007). Thus understood, existential and spiritual distress are grounded in despair over the limits to the self, and might be addressed by a re-evaluation of oneself so as to transcend these limits, and engender personal and spiritual growth. The confrontation with cancer thus instigates a process of self-transcendence. Self-transcendence refers to the idea that individuals facing vulnerability and mortality, as a response increase their capacity to expand their self-boundaries, and increase awareness of dimensions greater than the self (Coward and Reed 1996; Reed 2009). Self-transcendence comprises both psychological and spiritual components, and represents a holistic level of higher consciousness, relating to oneself, (significant) others, nature, and the cosmos (Maslow 1971). Self-transcendence has been shown to be important to mental health in general (Reed 2009); and its occurrence has been associated with an increased sense of spiritual wellbeing in the context of cancer (Coward 1991, 2003; Thomas et al. 2010). However, the mechanism in which a confrontation with vulnerability and mortality leads to a spiritual re-evaluation and ultimately to transcendence in the context of cancer, has not been extensively explored.

Transcending the limits to the self is a dynamic process in which the expanding and crossing of the boundaries of existence can take place in different movements, directions, and dimensions. Self-boundaries can be transcended temporally (in integrating one's past and future in a way 
that has meaning for the present), intrapersonally (toward self-acceptance, and finding meaning), interpersonally (by reaching out for, and connecting with others and one's environment), and transpersonally (by reaching out for, and connecting with dimensions beyond the typically discernible world) (Reed 2009); and can be actively pursued from the inside-outward, as happens when one reaches out beyond the self, and addresses or appeals to others, or to another reality, meaning or presence (inside-out transcendence); or from the outside-in (outside-in transcendence), if the boundaries to existence are crossed from the outside inward, and one is addressed and transformed by (significant) others, or by another reality, meaning, or presence (Ganzevoort 2006).

In existential psychotherapy, philosophy, and theology, these different dynamics, movements and directions for transcending the limits to the self, have been extensively explored in the middle of the 20th century. In this study, we base ourselves on two key-figures in these debates, Frankl and Tillich, since they represent two different notions on transcendence that can be helpful in understanding self-transcendence in the face of cancer. Transcending the boundaries to the self, according to Frankl, is the essence of existence, and entails consciously directing oneself away from, or beyond the self, towards something or someone other than oneself; be it a meaning to fulfill, or another being to encounter (Frankl 1988). A confrontation with the tragic triad of pain, death, or guilt, kindles, besides despair, the self-transcendent quality of humans to reach beyond themselves-beyond what Frankl calls 'ontological deafness and blindness' - towards the spiritual or noble part of human nature, so that the meaning of one's being can shine forth (Frankl 1955, 1988). For Frankl, this search for self-transcendence is constituted of three basic principles: the freedom of will, the will to meaning, and the meaning of life (Frankl 1955, 1988). The first principle, the freedom of will, implies that one is free to take a stand on the conditions that one is faced with. One is capable of resisting and braving even the worst conditions, Frankl argues, by choosing one's attitude towards these conditions (Frankl 1955, 1988). Even though one cannot change the conditions one is faced with, one can transmute these conditions and open up a different dimension to life, a spiritual dimension in which the self can be transcended, and can be healed. With the second principle, the will to meaning, Frankl suggests that the search for fulfillment of meaning and transcendence is the basic striving, or the primary concern, of human existence, and that all motivations or drives in life, such as happiness, power, or self-actualization, are mere derivatives or effects of this search for the fulfillment of meaning. The third principle concerns the meaning of life as such. The meaning of life, Frankl contends, is not arbitrarily made or given, but found responsibly by a valuing process containing creative, experiential and attitudinal values; one can find meaning in life by what one gives to the world in terms of one's work and creations (creative value); or by what one receives or takes from the world (experiential value) in terms of encounters (with another unique being) and experiences (of goodness, truth, beauty, nature, and culture); or even in the manner one faces a fate that one cannot change, that is, in how one suffers (attitudinal value) (Frankl 1988).

Whereas for Frankl, despair over death, pain and guilt can be transcended by a conscious outward search for meaning and transcendence, Tillich argues that it is exactly in accepting and embracing the impossibility of overcoming existential suffering and despair, that one can transcend despair. To believe in life in the face of death, in the self in the face of guilt and condemnation, in meaning in the face of doubt and meaninglessness, or in connectedness in the face of estrangement, Tillich maintains, is a manifestation of enormous courage and faith in what exceeds fact, and appearance (Tillich 2000). Existential anxiety, Tillich argues, requires self-affirmation 'in-spite-of' the circumstances and limits denying and negating the self of affirming itself. Such self-affirmation presupposes and relies on what Tillich calls the 'courage to be'; a faith rooted in 'a power of being' that is greater than the power of oneself, or the power of one's world (Tillich 2000, p. 155).

Tillich outlines three interwoven types of existential anxiety, in need of such courage or faith: ontic, moral, and spiritual anxiety (Tillich 2000). Ontic anxiety, or the anxiety of fate and death, is the most basic, universal and inescapable form of anxiety. It arises from awareness of the complete loss of self that is implied in death, and in the relative loss of the self that is implied in one's fate, or the contingency and unpredictability of personal existence (Tillich 2000). To affirm the self in light 
of ontic anxiety, one is in need of the courage to affirm one's life and oneself, despite death and fate. Moral anxiety, the threat to one's moral self-affirmation, or the anxiety of guilt, self-rejection and condemnation, deals with one's responsibility for one's being. It is concerned with the question of whether one-within one's finite freedom-contributes to the fulfillment of one's potentiality or destiny. Everyone, Tillich maintains, is responsible for one's life, and has to answer, if asked, what one has made of oneself. Actualization and fulfillment of the self, however, are not unlimited. They are bound by one's finite nature, and by the appeal of norms and values of what one 'should be' and 'ought to be' in one's community (Tillich 2000, 1956). Not having fulfilled one's potentiality, not having responded to what one 'ought to be', causes guilt and (self)-condemnation. For Tillich, to affirm the self in light of anxiety over this guilt, (self)-rejection and condemnation, one is in need of the courage to be as oneself, that is, the courage to accept oneself as accepted, despite one's moral flaws and being unacceptable (Tillich 2000). Spiritual anxiety, finally, concerns the threat of non-being to one's spiritual life, and deals with the anxiety of emptiness and meaninglessness caused by the estrangement of one's ultimate concern, or the spiritual center that gives ultimate meaning to existence. Paradoxically however, to affirm the self in light of spiritual anxiety, Tillich asserts, one is in need of the courage to participate in what one feels estranged from: ultimate concern and one's spiritual center.

Ontic, moral, and spiritual despair, Tillich argues, thus appeal to affirm the self by means of a courage that is rooted in what concerns one ultimately, and transcends the self. One is not necessarily aware of the source of this courage: "there are acts of courage in which we affirm the power of being, whether we know it or not. If we know it, we accept acceptance consciously. If we do not know it, we nevertheless accept it, and participate in it. And in our acceptance of that which we do not know the power of being is manifest to us" (Tillich 2000, p. 181). The courage to be, Tillich claims, has a revealing power: whenever one has the courage to take one's deepest suffering and anxiety upon oneself, one can (consciously or unconsciously) find and participate in the power of being that transcends everything that is (Tillich 2000).

If we understand spiritual re-evaluation in the face of cancer by means of Reed's, Frankl's and Tillich's conceptualization of transcending the limits to the self, we can understand spiritual re-evaluation as the process in which one tries to overcome existential anxiety or despair over loss of the self, by means of affirming the self. This anxiety over loss of the self takes three different shapes: ontic anxiety deals with anxiety over fate and death; moral anxiety concerns anxiety over guilt, self-rejection and condemnation; and spiritual anxiety refers to anxiety over doubt and estrangement from one's ultimate concern. Ontic, moral, and spiritual despair can be transcended by (1) taking a stand towards; (2) finding meaning in; and/or (3) accepting and embracing the self, 'in-spite-of' the circumstances and limits denying and negating the self of affirming itself. Transcending the limits to the self can be the result of a conscious outward movement, in which a person consciously reaches out for, and seeks transcendence by means of what concerns one ultimately; or of an inward movement, in which a person consciously or unconsciously feels sustained by a courage to be that is rooted in 'a power of being' that is greater than the power of oneself, or the power of one's world. This process of reorienting the self from despair over loss of the self to affirmation of the self, might lead to temporal, intra-, inter-, or transpersonal transcendence. See Table 1.

\subsection{Transcending the Self and Spirituality}

Having to (re)affirm life, oneself, or one's ultimate concern in order to overcome ontic, moral, or spiritual anxiety requires a personal response as to how one reconciles finitude and transcendence in one's life, and how one-in light of this-decides on what the nature of one's engagement with the finite and transcendent entails. In appealing to re-orient oneself on one's way of perceiving and being in the world, a confrontation with a life threatening illness like cancer, thus instigates a shift in one's spirituality. Spirituality is a complex construct with a variety of conceptual and operational definitions. Within the healthcare setting, connectedness, transcendence, personal meaning, and meaning making are generally seen as the basic components of spirituality (Puchalski et al. 2009, 2014; Weathers et al. 
2016). Connectedness refers in this context to the relationship with the self, with others, nature, the world, a higher power, meaning or presence; Transcendence has to do with the ability to transcend one's own suffering and to exceed one's restrictions and limitations; Finally, meaning and meaning making refer to the manner in which people give meaning to, or find meaning in life.

Table 1. Spiritual re-evaluation and self-transcendence.

\begin{tabular}{lll}
\hline $\begin{array}{l}\text { Anxiety Over } \\
\text { Loss of the Self }\end{array}$ & Self-Affirmation & Self-Transcendence \\
\hline $\begin{array}{l}\text { Ontic anxiety } \\
\text { (fate and death) }\end{array}$ & $\begin{array}{l}\text { Ontic affirmation: affirming life } \\
\text { (in taking a stand towards the conditions of Re-Evaluation } \\
\text { life; in finding meaning in suffering; in } \\
\text { accepting life despite fate and death). }\end{array}$ & $\begin{array}{l}\text { Temporal transcendence (integrating } \\
\text { past and future in meaningful present) }\end{array}$ \\
\hline $\begin{array}{l}\text { Moral anxiety } \\
\text { (guilt, self-rejection, } \\
\text { and condemnation) }\end{array}$ & $\begin{array}{l}\text { Moral affirmation: affirming the self as } \\
\text { oneself (in taking a stand towards the } \\
\text { fulfillment of oneself and one's destiny; in } \\
\text { finding meaning in one's works and } \\
\text { creations; in accepting the self despite being } \\
\text { unacceptable). }\end{array}$ & $\begin{array}{l}\text { Intrapersonal transcendence } \\
\text { (self-acceptance, fulfillment in life) }\end{array}$ \\
\hline $\begin{array}{l}\text { Spiritual anxiety: } \\
\text { (estrangement from } \\
\text { ultimate concern; } \\
\text { emptiness and } \\
\text { meaninglessness) }\end{array}$ & $\begin{array}{l}\text { Spiritual affirmation: affirming ultimate } \\
\text { concern (in taking a stand towards ultimate } \\
\text { concern; in finding ultimate meaning in } \\
\text { encounters and experiences; in accepting } \\
\text { affirmation of one's ultimate concern, } \\
\text { despite doubt and/or estrangement from } \\
\text { this ultimate concern). }\end{array}$ & $\begin{array}{l}\text { Intrapersonal transcendence } \\
\text { (connectedness with the self); } \\
\text { (connectedness with significant others } \\
\text { and environment); } \\
\text { and Transpersonal transcendence } \\
\text { (connectedness with dimensions } \\
\text { beyond the typically discernible world; } \\
\text { the significant, the sacred) }\end{array}$ \\
\hline
\end{tabular}

In this study, we adopt this concept of spirituality, and understand spirituality as the manner in which people seek, express and find meaning and purpose, and experience their connectedness to the moment, to the self, to others, and the significant, or sacred (de Jager-Meezenbroek et al. 2006; Puchalski et al. 2009, 2014). We moreover emphasize lived spirituality: "Lived experience is the raw material in which spirituality expresses itself" (Waaijman 2000). With this, we focus on lived spirituality, we emphasize that spirituality is closely related to one's personal life course. In this study, we understand spirituality furthermore as a universal human phenomenon, regardless of cultural or religious background (de Jager-Meezenbroek et al. 2006). In this perspective, religion and spirituality are separate, but connected concepts. Religion can offer content, form and meaning to spirituality, but spirituality can also be brought about without religious content, forms and meaning (Visser et al. 2013). Lastly, we understand this universal lived spirituality as a personal search for transcendence (Hill et al. 2000; Pargament 2013, 1997). Although spirituality is grounded in the everyday world, it is simultaneously characterized by a transcendent character due to an interruption, transcendence or deepening of that same world. This transcendent character is related to what concerns one ultimately, and can be sacred (with regard to the power of religion, faith, and a transcendent meaning or presence); vital (with regard to the power of the body, nature, the whole, being, life); and social (with regard to the power of the family, the community and the social environment) (van den Brink 2012).

\subsection{Spiritual Life Review as a Tool for Spiritual Re-Evaluation}

A life threatening illness creates a 'dangerous opportunity' for the self, as people confronted with illness, not only face the risk of losing their life and themselves, but are also presented with an opportunity to enrich, and significantly change themselves, and their life (Carel 2016; Frank 1991, 1998; Yalom 2008). This dangerous opportunity can be brought to fruition by telling the story of oneself, 
since in telling one's life story, one can re-evaluate the self, and modify one's way of perceiving and being in the world (Carel 2016; Frank 1991, 1998).

Illness, in other words, creates an occasion for re-evaluating life and the self, an occasion that can be actualized by telling the story of one's life (Frank 1998). Life stories allow for a so-called reflexive moment of self-esteem: how one evaluates oneself, depends on the interpretation of one's life story, since both self-esteem and self-contempt "follow the fate of interpretation" (Ricœur 1992, p. 179). People provide their lives with unity, coherence, meaning, and purpose by constructing internalized and evolving narratives of the self (McAdams 2001, p. 100). These narratives-also called life stories-enable to comprehend the present, explain the past, and give direction to the future (McAdams 2009; Ricœur 1984, 1991). Life stories are distinctive for their correlative character: life stories enable one to make connections between events, people and places that would otherwise be separate facts. This correlative character not only gives direction to a life story, but also to the person behind the story. Life stories show how people see themselves in the midst of others, and how they have become, and remain, themselves. Life stories, moreover, give insight into the guiding meaning, values, principles and assumptions one has learned to embrace in the midst of the vicissitudes of human existence (Ganzevoort 2001; Ganzevoort and Visser 2007; Ricœur 1984, 1992).

Life review interventions enable people to review their life in a structured fashion, and tell their life story from an evaluative perspective. Life review interventions focus on the re-evaluation of life events, and on the integration of positive and negative life events into a coherent life story (Pinquart and Simon 2012; Westerhof et al. 2010; Westerhof and Bohlmeijer 2014). In a spiritual life review intervention, one reviews, evaluates, and constructs one's life story in light of one's ultimate concern. A spiritual life story thus has a dual nature: it is both a so-called ego document in which an understanding of the development of one's own person is constructed on the basis of one's own life experience (McAdams 1996), as well as an exploration of the spiritual foundation of one's life (Staude 2005; Wakefield 1990).

Life review interventions have been shown to be beneficial for existential wellbeing (Bauereiß et al. 2018), and have been demonstrated to lead to ego integrity; the integration of positive and negative memories into a meaningful entirety, resulting in a positive acceptance of one's own life (Kleijn et al. 2018; Pinquart and Simon 2012). Ego integrity is often associated with meaning and meaning making (Westerhof et al. 2010). The relationship with spirituality has been less investigated, but there are indications that ego integrity and spirituality are interrelated (Jeong and Oh 2015).

In this study, we explore the impact of a spiritual life review intervention on spiritual re-evaluation, spiritual growth, and psycho-spiritual wellbeing. We expect this intervention to facilitate the re-evaluation of one's life in light of one's ultimate concern, and thus to not only lead to ego-integrity, or the positive acceptance of one's life and oneself; but also to self-transcendence, and a strengthened spirituality, or the connectedness with the self, the other, the significant or sacred.

\section{Materials and Methods}

\subsection{Study Design and Population}

This study was a one phase mixed methods effect study, consisting of a qualitative explorative study by means of semi-structured interviews aimed at understanding how spiritual life review (SLR) impacts spiritual re-evaluation, and self-transcendence caused by the confrontation with cancer; and a quantitative single arm effect study with a pre-post measurement, investigating the effect of the intervention on spirituality, ego integrity, and psycho-spiritual wellbeing.

Eligible participants were adult cancer survivors (all cancer types; early stages, and chronic or returning types of cancer) who had completed their main treatment 6 months prior to the study (all treatment modalities); Participants were excluded if they suffered from severe cognitive impairment, were currently under psychological or psychiatric treatment, or were not sufficiently proficient in 
Dutch. Eligibility of participants was assessed during an intake with the researcher and facilitator of the intervention.

The study was approved by the EMGO institute (now part of the Amsterdam Public Health Research Institute), and the Medical Ethics Committee of the Amsterdam University Medical Center, location VUmc, The Netherlands. Cancer survivors were recruited between January 2012, and August 2014 in Amsterdam University Medical Center, location VUmc, and in 4 independent regional centers for psychosocial oncological support. Participants were informed about the study and intervention by means of information material at these locations (flyers, posters), publicity in local newspapers, magazines, and online articles, and were incidentally referred by healthcare professionals (specialists, nurses) and volunteers. A total of 73 people expressed interest in the intervention, and were assessed for their eligibility for the study. 57 cancer survivors were included, provided informed consent, and completed the baseline questionnaire (T0); 56 started the intervention; 48 finished the intervention and completed the post intervention assessment (T1); 44 completed up to 9 months post intervention (T2, T3); 33 participants were included for an interview (see the flowchart, Appendix A). Dropout rate for the intervention was low (14.3\%).

Participants were primarily female; were on average 57 years old (range 29-73), were mostly single; had children; and had mostly followed higher and medium education. Concerning their (religious) worldview, they mostly identified as 'bricoleur', having developed a personal worldview; as Christian; or as not having a religion or specific worldview. Concerning their affinity with writing, most participants indicated that they liked to write, but did not write often (see Table 2: demographic characteristics of the participants).

Table 2. Demographic characteristics of the participants.

\begin{tabular}{|c|c|c|c|c|c|}
\hline \multirow[b]{2}{*}{ Scale } & & \multicolumn{2}{|c|}{$(n=57)^{1}$} & \multicolumn{2}{|c|}{$(n=33)^{2}$} \\
\hline & & Distribution & $\%$ & Distribution & $\%$ \\
\hline \multirow[t]{2}{*}{ Sex } & Male & 6 & 10.5 & 5 & 15.2 \\
\hline & Female & 51 & 89.5 & 28 & 84.8 \\
\hline \multirow[t]{2}{*}{ Age } & Mean (SD) & $56.68(9.2)$ & & $57.73(9.1)$ & \\
\hline & Range & $29-73$ & & $29-73$ & \\
\hline \multirow{4}{*}{ Marital status } & $\begin{array}{l}\text { Married/long-term } \\
\text { relationship }\end{array}$ & 24 & 42.1 & 19 & 57.6 \\
\hline & Divorced & 16 & 28.1 & 8 & 24.2 \\
\hline & Widowed & 5 & 8.8 & 2 & 6.1 \\
\hline & Never married & 12 & 21.0 & 4 & 12.1 \\
\hline \multirow{2}{*}{ Children } & Yes & 43 & 75.4 & 26 & 78.8 \\
\hline & No & 14 & 24.6 & 7 & 21.2 \\
\hline \multirow{4}{*}{ Education } & High & 31 & 54.39 & 22 & 66.6 \\
\hline & Medium & 23 & 40.35 & 10 & 30.4 \\
\hline & Lower & 0 & 0 & 0 & 0 \\
\hline & Different & 3 & 5.26 & 1 & 3.0 \\
\hline \multirow{4}{*}{$\begin{array}{l}\text { Worldview/ } \\
\text { religion }\end{array}$} & Christian & 18 & 31.6 & 10 & 30.3 \\
\hline & Humanistic & 3 & 5.3 & 2 & 6.1 \\
\hline & Personal bricolage & 21 & 36.8 & 13 & 39.4 \\
\hline & No religion & 15 & 26.3 & 8 & 24.2 \\
\hline \multirow{3}{*}{$\begin{array}{l}\text { Affinity with } \\
\text { writing }\end{array}$} & Affinity, writing often & 12 & 21.1 & 6 & 18.2 \\
\hline & Affinity, not writing often & 36 & 63.2 & 21 & 63.6 \\
\hline & No affinity & 9 & 15.8 & 6 & 18.2 \\
\hline \multirow{4}{*}{ Tumor type } & Breast cancer & 27 & 47.4 & 16 & 48.5 \\
\hline & Hematological cancer & 10 & 17.5 & 7 & 21.2 \\
\hline & Different & 10 & 17.5 & 7 & 21.2 \\
\hline & Unknown & 10 & 17.5 & 3 & 9.1 \\
\hline
\end{tabular}

${ }^{1}$ Demographic characteristics at baseline (T0). ${ }^{2}$ Demographic characteristics of qualitative interview study. 


\subsection{Intervention}

The intervention 'Spiritual Life Review' (SLR) aims to facilitate spiritual re-evaluation and self-transcendence; and strengthen spirituality and psycho-spiritual wellbeing by interpreting, and constructing one's personal development in light of one's spirituality. SLR operates on the hypothesis that the methodical reflection on, writing, and presentation of one's life story in light of existential and spiritual themes, facilitates spiritual re-orientation, and ultimately spiritual growth, and psycho-spiritual wellbeing.

Participants methodically engage in SLR during 8 group sessions in three parts, over a 4-month period. In the first part (Session 1-4), participants reflect on the development of existential and spiritual themes in their life. Session 1 is an introductory session; session 2 focuses on spirituality, receptivity, and early youth; session 3 on autonomy and adolescence, and session 4 on connectedness and adulthood. By means of structured reflection on these existential and spiritual themes, participants reflect on themselves, and gain a constructed insight into their lived spirituality, that is in their lived experience of the connectedness with themselves, their significant others, and a significant or sacred meaning or presence. In the second part of the intervention (session 5 and a writing intermission) the participants configure their spiritual life story; in session 5, participants map, emplot, and present their personal development in light of their lived spirituality by means of a so-called biographical roadmap; and between session 5 and 6 participants write their spiritual life story accordingly. In the third and final part (session 6-8), participants present their spiritual life story. Each presentation is concluded with a small wishing well ritual, and in the final session the intervention as a whole is concluded by a farewell ritual.

\subsection{Outcome Measurements}

For the qualitative research aimed at understanding how spiritual life review (SLR) impacts spiritual re-evaluation and self-transcendence in the context of cancer, semi-structured interviews were conducted at 9 months after the intervention. In these interviews, participants were asked to talk about their spirituality; and about the impact of the confrontation with cancer, and their participation in SLR on the development of their spirituality. For an interview topic list, see Table 3. Interviews were audiotaped and transcribed verbatim.

Table 3. Interview topics.

\begin{tabular}{|c|c|}
\hline Key Questions & Aspects \\
\hline $\begin{array}{l}\text { - } \quad \text { How would you describe your own spirituality? } \\
\text { (How) has your illness impacted/changed } \\
\text { your spirituality? } \\
\text { (How) has the intervention impacted/changed } \\
\text { your spirituality? }\end{array}$ & $\begin{array}{l}\text { - What is of ultimate concern (connectedness } \\
\text { with the self, significant others, and a significant } \\
\text { or sacred meaning or presence) } \\
\text { - } \quad \text { Connectedness with ultimate concern } \\
\text { - } \quad \text { Sources of inspiration } \\
\text { - } \quad \text { Convictions/beliefs/worldview } \\
\text { - } \quad \text { Lived spirituality/practices in daily life }\end{array}$ \\
\hline
\end{tabular}

For the quantitative research, concerning the impact of SLR on spiritual growth, and psycho-spiritual wellbeing, patient reported outcomes were measured at baseline, post intervention, and after 3 and 9 months follow-up. Primary patient reported outcome measurements were the SAIL for measuring spirituality and spiritual growth (Spiritual Attitudes and Involvement List, 26 items, item score range 1-6; three dimensions, seven subscales: connectedness to an inner strength (meaningfulness, trust, acceptance); connectedness with the environment (caring for others, connectedness with nature); connectedness with the transcendent (transcendent experiences, spiritual activities) (de Jager Meezenbroek et al. 2012)); and the Dutch RYFF (scales of psycho-spiritual wellbeing, 49 items, item score range 1-6; two dimensions, eight subscales: psychological wellbeing (positive relations, autonomy, 
environmental mastery, personal growth, purpose in life, and self-acceptance) spiritual wellbeing (inner strength, relationship with a higher power) (van Dierendonck 2004)). The secondary outcome measurement was the NEIS, for measuring ego-integrity, or the experience of wholeness and meaning in life, even in spite of negative experiences (Northwestern Ego Integrity Scale, 9 items, item score range 1-6; two subscales: ego integrity and despair (Kleijn et al. 2016)).

\subsection{Analysis}

\subsubsection{Qualitative Analysis}

Interview data were coded, categorized and analyzed, both iteratively and reflexively, by two independent coders in Atlas.ti, and Excel. The coding and analysis process used both inductive elements (based on, and emerging from the empirical data) and deductive elements (based on, and emerging from theoretical concepts), so as to remain close to the interview data, but also build on, and engage with, earlier established empirical and theoretical insights. Interview data were coded in a two-stage process in Atlas.ti. Data were first coded exploratively, by performing axial coding based on general concepts such as spirituality, illness, and transformation, in order to gain a general understanding of the themes and topics relevant for the development of the participants' spirituality. Data were consequently coded substantively, by performing selective coding by means of a detailed coding scheme, based on the insights gained from the explorative coding cycle, as well as relevant theoretical concepts. The coding scheme included in vivo, descriptive, and process codes. After coding 3 pilot interviews, the definitive coding scheme was determined (see Appendix B). For each participant, a coding scheme was compiled by both coders in Excel. Coding schemes were compared, in case of divergent interpretations discussed, and joint coding schemes were compiled. These joint coding schemes, finally, were compiled in a cumulative coding scheme for all participants.

\subsubsection{Quantitative Analysis}

Patient reported outcomes were entered manually in SPSS, and spot-checks were conducted to ensure a correct data input. Changes over time in spirituality, ego integrity, and psycho-spiritual wellbeing were assessed by means of SPSS via a linear mixed models analysis (LMM), with a fixed effect for measurement-time and a random effect for subjects. Post-hoc analyses were performed to assess which measurements differed significantly (via LMM). Post-hoc analyses were corrected for multiple testing by Bonferroni correction. Effect estimates (b) of $>0.5$ ( $10 \%$ on a 5-point scale) were considered clinically relevant. Effect sizes $(B)$ were calculated by dividing the difference in change since the baseline by the pooled standard deviation, at the separate points in time (post-intervention, three months, and nine months past intervention). Effect sizes of 0.2 were categorized as small, 0.5 as moderate, and 0.8 as large (Cohen 1977).

\section{Results}

In the following, we present the results of our study. In order to understand how SLR impacts spiritual re-evaluation and self-transcendence, we first present the mechanism of spiritual re-evaluation before participants took part in the intervention SLR. We then present the results on the spiritual re-evaluation participants experienced after taking part in the intervention. Finally, we introduce the results of our pre-post intervention study on the impact of the intervention on spiritual growth and psycho-spiritual wellbeing.

\subsection{Re-Evaluation before the Intervention}

The confrontation with cancer resulted in almost three quarters (23/33) of the participants being anxious over their fate and confrontation with death. A third of these participants tried to overcome this anxiety by affirming life despite fate and death, while almost half (11/23) of the participants anxious over fate and death tried to overcome this anxiety by finding meaning in their suffering. Almost a third 
(10/33) of the participants experienced spiritual despair over estrangement from ultimate meaning in their life. For another third (13/33) of the participants however, their confrontation with their illness made them strengthen their connectedness with their ultimate concern, primarily with their significant others (8/33). While for one fifth (6/33) of the participants, their diagnosis necessitated them to really be aware of themselves and open up to themselves. See Table 4 . The confrontation with cancer thus primarily impacted ontic anxiety and affirmation, and temporal self-transcendence. The confrontation with cancer impacted, to a lesser extent, spiritual anxiety and affirmation, and moral affirmation. In the following, each of these developments is further described.

Table 4. Spiritual re-evaluation before the intervention.

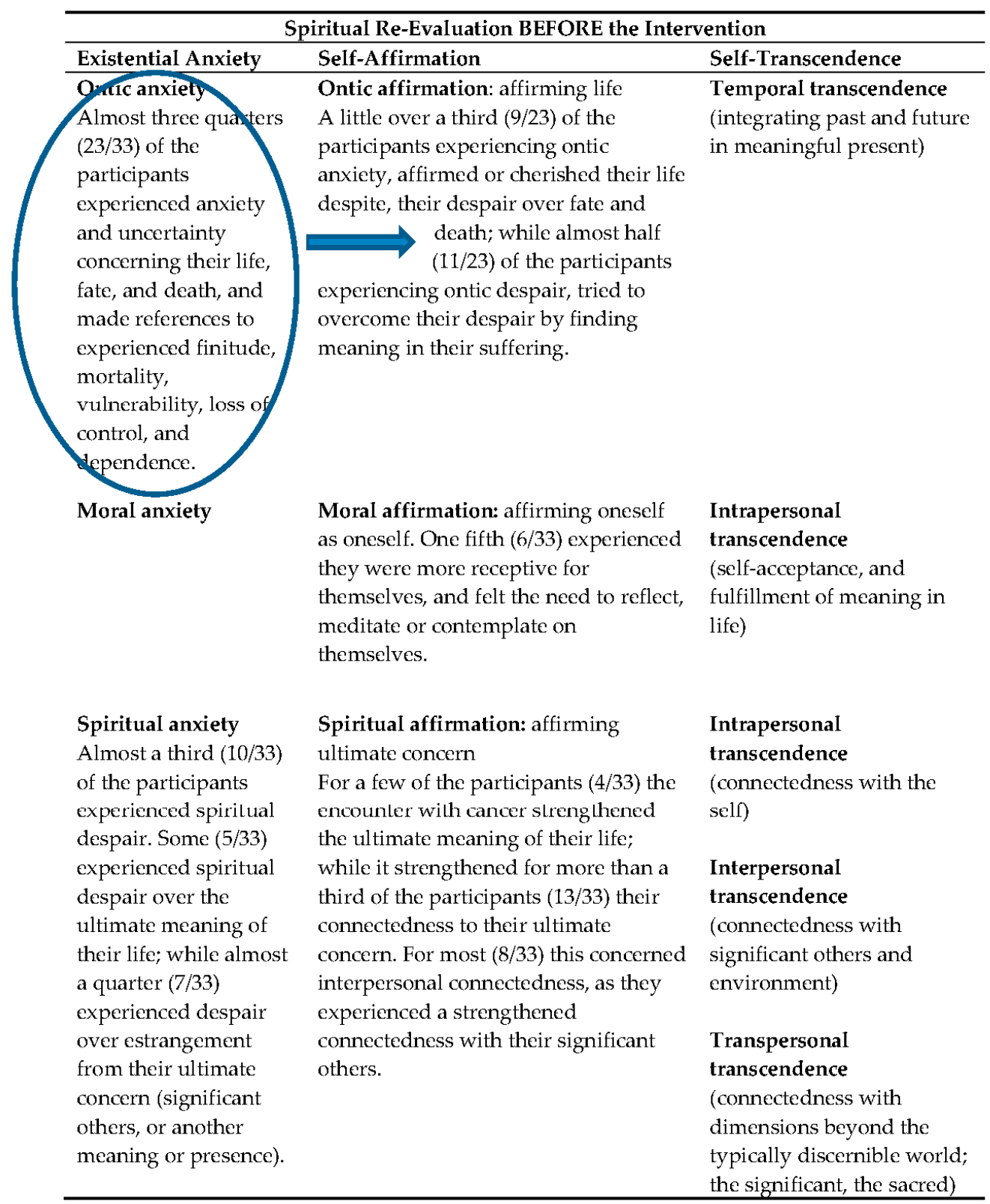

\subsubsection{Ontic Reorientation: From Ontic Anxiety to Ontic Affirmation}

Despair over fate and death: The confrontation with cancer resulted for more than two-thirds of the participants (23/33) in some form of ontic despair: these participants experienced anxiety and uncertainty concerning their life, fate, and death, and made references to experienced finitude, 
mortality, vulnerability, loss of control, and dependence. The confrontation with cancer made them aware of the fragility of life, and the reality of death: it made their finite human nature very real and palpable (resp. 48); it put death at their doorstep (resp. 47); they felt as if they had been sitting at the grim reaper's lap (resp. 24) or realized: "I could die from this" (resp. 23), and "Life can just be over" (resp. 11). These participants experienced a deeply felt uncertainty with regards to the future and their time left to live: "How long do I have left" (resp. 40); "How much time do I have now?" (resp. 19) "Will I still be around next year?" (resp. 42); "What should I do now? How long? And when will I die?" (resp. 16); and experienced confusion about their fate and destiny (resp. 17, 33, 43); Other respondents felt vulnerable, and 'naked' (resp. 35); or lost trust in life: "What if things go wrong?" (resp. 6). Yet, others just felt deeply afflicted by it all (resp. 38); or found themselves thrown in a complete panic because of the diagnosis (resp. 15, 21); found their diagnosis and illness extremely frightening (resp. 26); could not acknowledge their illness out of fear (resp. 27); or got angry and sad: "Things will never be alright again" (resp. 54). They lost control over their life (resp. 14); were blown away by the diagnosis (resp. 10); or perceived the disease as 'an overwhelming tidal wave' that caused them to lose everything (resp. 12).

Taking a stand towards the conditions of life: affirming life despite fate and death. A little over a third of the participants experiencing ontic anxiety (9/23) countered this anxiety by (positively) relating to their own life, despite their perceived vulnerability, finiteness and dependence. They did this by affirming their life: "I live until the contrary is proven" (resp. 26), or by affirming the finite nature of life (resp. 11, 19). Others tried to be at peace with their own death (resp. 16), or with their life with illness (resp. 47). While yet others were, despite everything, delighted to be still alive (resp. 14) or were euphoric having survived their illness and treatments: "Hurray I'm still here! I have conquered my illness, having life is enough!" (resp. 6); or cherished life as a consequence: "It is a shame to waste life after all I have sacrificed for it" (resp. 12); "I now enjoy life twice as much" (resp. 27).

Finding meaning in suffering: Almost half of the participants experiencing ontic despair (11/23) tried to overcome this despair by finding meaning in their suffering, or in their encounter with cancer. Some saw their illness as a retreat, and perceived their illness as something positive: "it is an open and sensitive period, it makes you appreciate the basic things" (resp. 6); or saw their illness as a catalyst for awareness of what is really important and of value to them (resp. 19); Yet others perceived their illness as a gift (resp. 5); as an opportunity to work on their spiritual development (resp. 2); or as a learning process in surrender, acceptance and gratitude (resp. 36). Yet, others now worried less about futilities and perceived their vulnerability as liberating (resp. 42); or felt the inner necessity and responsibility to complete life well, and to make the very best of it (resp. 35). Some participants saw their illness as a sign that they had to look for new meanings in life, and find a new balance between body and mind (resp. 23), or between body, mind and environment (resp. 15). Two participants finally gave meaning to their survival of cancer: one participant saw her illness as predestined, as something that to be, and understood her survival as proof that she "was still allowed to be around" (resp. 38); While another saw her survival as a hopeful sign for the future: "If I can endure this, what can I not do?" (resp. 12).

\subsubsection{Moral Reorientation: From Moral Anxiety to Moral Affirmation}

Taking a stand towards the self: awareness of the self. Almost one fifth of the participants (6/33) experienced that the illness made them more aware of, and receptive to themselves: the confrontation with cancer opened these participants up to themselves, and motivated them to think about themselves (resp. 15); or forced them to reflect (resp. 12) meditate (resp. 16) or contemplate (resp. 35) on themselves; or gave them the time and space to further develop their spirituality (resp. 2, 5).

\subsubsection{Spiritual Re-evaluation: From Spiritual Anxiety to Spiritual Affirmation}

Meaninglessness: for some participants (4/33), their illness sparked spiritual despair about the ultimate meaning of their life. Their confrontation with cancer affected their belief that by living a good and spiritual life, one will be protected from poor health and harm (resp. 14) or that 'pure love' 
will protect them from illness (resp. 33). Other participants experienced the illness as a punishment from God (resp. 43), and asked God in despair: 'why do you do this to me?' (resp. 32).

Estrangement from ultimate concern: a fifth of the participants (7/33) experienced spiritual despair, since their illness had a negative impact on their connectedness with their significant others, or another meaning or presence. Some participants (3/33) experienced interpersonal estrangement, and indicated that their illness prevented them from truly being present for their significant others (resp. 22, 36); or, that during their illness, their social environment had been less present for them (resp. 5); other participants (4/33) suffered from transpersonal estrangement, as they missed their connectedness with a transcendent meaning, or presence: these participants felt estranged from their Buddhist way of life, since they could no longer practice their Buddhism as they wanted to (resp. 6); or missed the presence of 'pure love', making them close themselves off for this pure love in return (resp. 33); while others missed the presence of God, making them feel abandoned and angry with God (resp. 32); or making them desperately reach out, and seek help and involvement from God and the cosmos (resp. 15).

Strengthening ultimate meaning: for a few of the participants (4/33), the experience of illness developed or reinforced the ultimate meaning of their life. These participants articulated a vision on the afterlife: "I now have a picture of life after death" (resp. 21); or: "I now know: I am just a heap of molecules, but the spirit lives on" (resp. 48); or felt strengthened in their beliefs about life and the afterlife: "life as it is now, is not as it is intended" (resp. 3). For other respondents, their illness helped them strengthen their faith and belief in God: "diseases are like arrows of discouragement, but faith is your shield and my house with God is ready" (resp. 10).

Connectedness with ultimate concern: approximately one third of the respondents (13/33) experienced-because of their illness-an increased connectedness with their ultimate concern. For almost a quarter of the participants (8/33), this concerned interpersonal connectedness, as they experienced a strengthened connectedness with their significant others. These participants not only sensed that their confrontation with cancer made them more receptive to, and reach out for their significant others (resp. 14, 22, 42), or their faith community (resp. 10); but they also observed an increased presence of their significant others, as their social environment and significant others were more available and present during their illness (resp. 22, 32, 36), or had real and sincere attention (resp. 42,51), recognition (resp. 50) or encouragement (resp. 10) for them. For a fifth of the participants (7/33; 21\%), this strengthened connectedness was transpersonal, as they experienced that the illness made them more connected to another meaning or presence. They were not only more receptive to, and reaching out for Jesus (resp. 15, 21), for God (resp. 10, 22), for a basic, foundational power (resp. 6) or for the sacred ground of existence (resp. 25); they also experienced an increase in the presence and support of a universal force (resp. 12), God (resp. 22), Jesus (resp. 15) or Jesus and God (resp. 10, 21).

\subsection{Re-Evaluation after the Intervention}

As a result of the intervention, almost a third of the participants (10/33) indicated that the intervention enabled them to appreciate, and accept life, and be future oriented. Moreover, all participants (33/33) noted a change in how they related to, and affirmed themselves. For more than three quarters of the participants (26/33) the intervention strengthened their connectedness to themselves, others, or a significant other meaning or presence. See Table 5. The intervention thus primarily impacted moral and spiritual re-evaluation and affirmation, and intra, and interpersonal transcendence. The intervention impacted to a lesser extent ontic reorientation and affirmation, and temporal transcendence. In the following, each of these developments is further described. 
Table 5. Spiritual re-evaluation after the intervention.

\begin{tabular}{|c|c|c|}
\hline \multicolumn{3}{|c|}{ Spiritual Re-Evaluation AFTER the Intervention } \\
\hline Existential Anxiety & Self-Affirmation & Self-Transcendence \\
\hline Ontic anxiety & $\begin{array}{l}\text { Ontic affirmation: affirming life Almost a } \\
\text { third of the participants (10/33) indicated that } \\
\text { the intervention enabled them to appreciate, } \\
\text { and accept life, and be future oriented. }\end{array}$ & $\begin{array}{l}\text { Temporal } \\
\text { transcendence } \\
\text { (integrating past and } \\
\text { future in meaningful } \\
\text { present) }\end{array}$ \\
\hline Moral anxiety & $\begin{array}{l}\text { Moral affirmation: affirming oneself as oneself } \\
\text { As a result of the intervention, all participants } \\
\text { ( } 33 / 33 \text { ) noted a change in how they related to } \\
\text { and affirmed themselves. More than half } \\
\text { (18/33) observed a basic } \\
\text { presence and openness for } \\
\text { themselves that was previously unknown to } \\
\text { them; A little over a third of the participants } \\
\text { (13/33) could affirm themselves, and be mild } \\
\text { and non-judgmental towards } \\
\text { themselves; Almost half of the } \\
\text { participants (16/33) were now able to accept } \\
\text { themselves as themselves, or feel accepted as } \\
\text { themselves; Almost a quarter of the } \\
\text { participants (8/33) indicated that the } \\
\text { intervention helped to (re)affirm their } \\
\text { understanding of the meaning of their life. }\end{array}$ & \\
\hline Spiritual anxiety & $\begin{array}{l}\text { Spiritual affirmation: affirming ultimate } \\
\text { concern. For more than three quarters of the } \\
\text { participants (26/33) the intervention } \\
\text { strengthened their } \\
\text { connectedness to themselves, others, } \\
\text { or a significant other meaning or presence. Fo } \\
\text { a quarter of the participants ( } 9 / 33 \text { ) this } \\
\text { concerned intrapersonal connectedness, as the } \\
\text { intervention enabled them to discover, } \\
\text { manifest and connect to another, previously } \\
\text { unknown side of themselves; Participants } \\
\text { moreover observed an increased interpersonal } \\
\text { connectedness: Almost one fifth of the } \\
\text { participants (6/33) indicated that they opened } \\
\text { up to (significant) others. In addition, } \\
\text { participants tried to be more, and differently } \\
\text { present for their significant others (11/33). And } \\
\text { were more aware of the presence of others for } \\
\text { themselves }(9 / 33 \text { ). Finally, some participants } \\
\text { (4/33) indicated an intensified transpersonal } \\
\text { connectedness, as the intervention enabled a } \\
\text { reconfirmation of their connectedness with } \\
\text { another presence or meaning }\end{array}$ & $\begin{array}{l}\text { transcendence } \\
\text { (connectedness rith } \\
\text { the self) } \\
\text { Interpersonal } \\
\text { transcendence } \\
\text { (connectedness yith } \\
\text { significant other; } \\
\text { and environmght) } \\
\text { Transpersonal } \\
\text { transcendence } \\
\text { (connectedness with } \\
\text { dimensions beyond } \\
\text { the typically } \\
\text { discernible world; } \\
\text { the significant, the } \\
\text { sacred) }\end{array}$ \\
\hline
\end{tabular}




\subsubsection{Ontic Reorientation: From Ontic Anxiety to Ontic Affirmation}

Affirming life despite fate and death: almost one third of the participants (10/33) indicated that the intervention enabled them to positively relate to, and reaffirm their life. The intervention helped them to accept and appreciate life, focus on the life that remained, and be future-oriented, despite their fate and death. After the intervention, these participants could finally face life (resp. 35), including the insecurity and fear inherent to their illness (resp. 24). They could accept life, and be grateful for life as it was now (resp. 22), or could come to terms with their illness and could start healing (resp. 27). They no longer looked back at what had been lost, but shifted their focus to the life that remained (resp. 25); or were able to put their illness into perspective, confirm life, and be future-oriented (resp. 19, 40). They could accept their fate, and accept life as it was now (resp. 14); no longer felt the need to paint a rosy picture of their life, and make it seem more beautiful (resp. 15); and were more aware that life is precious, and that they were living in extra-time now (resp. 38).

\subsubsection{Moral Reorientation: From Moral Anxiety to Moral Affirmation}

Taking a stand towards the self: opening up to the self. After the intervention, more than half of the participants (18/33) observed an increased awareness and acknowledgement of themselves. They indicated that the intervention helped them to open up, and be more receptive to (unknown parts) of themselves. They could now reflect on themselves in a truthful manner (resp. 5, 50); could set up frank, and honest dialogues with (the deepest part of) themselves (resp. 15); and could be present for themselves (resp. 12). They now dared to acknowledge hidden parts of themselves (resp. 11); or could finally testify to traumatic events that they had never acknowledged before (resp. 43). These participants could now acknowledge their own process (resp. 2, 23); and how this had shaped them (resp. 17, 33); and had built their strength (resp. 40). They were now receptive and aware of their own vulnerable side (resp. 24, 25); their deepest thoughts (resp. 42); depths (resp. 36), inner source (resp. 35), or inner strength (resp. 6, 19).

Affirming the self: a little over a third of the participants (13/33) indicated that, after the intervention, they could affirm themselves, and be mild and non-judgmental towards themselves. These participants could now look at themselves differently: more neutral, and from within their own process (resp. 14). They could be nicer (resp. 25); "lighter, and less tough" (resp. 32); more understanding and milder (resp. 26); or sympathetic for themselves, and feel love (resp. 6, 17). They could be present for (resp. 19), or reflect on (resp. 54) themselves without judgement; they no longer condemned themselves (resp. 3), but could confirm their thoughts: "you may have these thoughts" (resp. 13); or their positive and negative sides: "all of it may be there" (resp. 27, 35); and feel compassion for themselves (resp. 21).

Accepting oneself as oneself: after the intervention, almost half of the participants (16/33) were now able to accept themselves as themselves, or feel accepted as themselves. These participants indicated that - as a result of the intervention - they attained a sense that they may truly be who they are: "you are good the way you are" (resp. 2, 3, 5, 12, 13, 17, 19, 21, 25, 26, 27, 38, 47, 48, 51, 54). They felt they were allowed to be themselves in all their facets (resp. 26); states of mind (resp. 3); and with everything there is to them (resp. 5,27). They had learned to see themselves as worthy human beings: "I must be doing well, otherwise I would not be receiving this" (resp. 12). They could accept themselves by means of their inner strength (resp. 2, 19); felt sustained by an always present source of love (resp. 5); or by their own spirituality (resp. 21). Participants no longer suffered from self-blame and self-rejection (resp. 25); they could now truly appreciate themselves (resp. 17, 51); and insisted on being appreciated by others as well (resp. 13); or realized they were always appreciated, even when it was unbeknownst to them (resp. 54).

Finding meaning in life: almost a quarter of the participants (8/33) indicated that the intervention helped to (re)affirm their understanding of the meaning of their life. These participants could once again be confident that life takes a meaningful course, and that things happen as they should (resp. 2, 12); making them who they are (resp. 25, 54); making them stronger, as intended (resp. 13), or giving them the opportunity to push further, and make something of life (resp. 38). Others developed a 
philosophy of life in which life events acquire meaning (resp. 17); or integrated their philosophy of life in their own life story (resp. 33).

\subsubsection{Spiritual Re-Evaluation: From Spiritual Anxiety to Spiritual Affirmation}

Strengthening ultimate meaning: for some participants (4/33), the intervention helped them to strengthen their understanding of ultimate meaning. They were able to reorient themselves on the ultimate meaning of life (resp. 14); or were able to reconfirm their (pre-existing) understanding of real connectedness between people (resp. 48, 51); or of God and Jesus (resp. 10) as the ultimate meaning of life.

Strengthening connectedness with ultimate concern: for more than three quarters of the participants (26/33), the intervention strengthened their connectedness to themselves, others, or a significant other meaning or presence.

For a quarter of the participants (9/33), this concerned intrapersonal connectedness, as the intervention enabled them to discover, manifest and connect to a different, previously unknown side to themselves. These participants indicated that they (re)discovered an inner strength (resp. 2, 3, 17, 19, 35, 36); a fundamental force (resp. 6); a sacred ground (resp. 25); or deepest self (resp. 15). These participants felt supported by this inner strength (resp. 2); wished to hold on to this inner strength (resp. 19); to manifest this part of themselves (resp. 15); and make decisions based on it (resp. 35).

Participants moreover observed an increased interpersonal connectedness, since their connectedness with their (significant) others strengthened because of the intervention. Almost one fifth of the participants (6/33) indicated that they opened up to (significant) others, and allowed others to be closely involved in their life (resp. 16); or were generally more open to others (resp. 17, 19, 23); or specifically to their loved ones (resp. 12) or partner (resp. 38). In addition, participants tried to be more, and differently present for their significant others (11/33). They tried to see others with more depth (resp. 35); or tried to consciously acknowledge them, and be unconditionally present for them (resp. 38). They could now be present without judgment (resp. 19, 22); or had a better understanding of, and were milder towards (significant) others (resp. 25, 26, 27, 32, 42, 47, 54). Participants also indicated that the intervention changed their awareness and acknowledgement of the presence of others for themselves (9/33): participants recognized that important others were, at crucial moments or continuously, there for them (resp. 3, 5, 51,54). Finally, participants made important others intimate witnesses to themselves and their lives, by sharing their spiritual autobiography with them (resp. 13, $16,25,43,48)$.

Some participants (4/33) indicated an intensified transpersonal connectedness, since the intervention made them (even) more receptive to Jesus (resp. 15); God (resp. 25) and life, nature and the greater good (resp. 54). They could moreover reconfirm the presence of God as a witness to their lives (resp. 25); and realized that they can always place their worries with God or Jesus (resp. 15); or could reconfirm their choice for God and Jesus as enriching their life (resp. 10).

\subsection{Impact of the Intervention on Spiritual Growth, Ego-Integrity and Psycho-Spiritual Wellbeing}

Participants improved statistically significantly in spirituality, ego integrity, and psycho-spiritual wellbeing. Treatment benefits were small to moderate, and occurred immediately, three months and nine months after the intervention.

\subsubsection{Spirituality and Spiritual Growth}

Concerning spirituality and spiritual growth, participants improved significantly three months after the intervention in overall spirituality $(p=0.001)$; in meaningfulness $(p=0.007)$, and acceptance $(p=0.010)$ (together connectedness with an inner strength); and in transcendent experiences $(p=0.004)$, and spiritual activities $(p<0.001)$ (together connectedness with the transcendent). The improvement on spiritual activities continued to be significant also at nine months after the intervention $(p=0.014)$. Treatment benefits were small $(B<0.5)$, and not clinically relevant $(b<0.5 ; 10 \%$ on a 5 -point scale). 
Participants did not report significant improvement on the subscales connectedness with nature, or caring for others (together connectedness with the environment), or on the subscale trust (connectedness with oneself). See Table 6.

Table 6. Spirituality and Spiritual Growth (SAIL). ${ }^{1,2}$.

\begin{tabular}{|c|c|c|c|c|c|c|}
\hline Dependent Variable & Baseline & $\begin{array}{c}p(\mathrm{H} 0: \mathrm{T} 0=\mathrm{T} 1 \\
=\mathrm{T} 2=\mathrm{T} 3)\end{array}$ & $\begin{array}{c}\text { Treatment } \\
\text { Effect }\end{array}$ & $\begin{array}{c}p \text { Bonferroni } \\
\text { Correction } \\
(\mathrm{p}<0.05 / 3=0.017)\end{array}$ & $\begin{array}{c}\text { Effect } \\
\text { Estimate } b\end{array}$ & $\begin{array}{l}\text { Effect } \\
\text { Size } B\end{array}$ \\
\hline Overall spirituality & 4.04 & 0.007 & $\mathrm{t} 0-\mathrm{t} 2$ & 0.001 & 0.204 & 0.397 \\
\hline Meaningfulness & 4.11 & 0.048 & $\mathrm{t} 0-\mathrm{t} 2$ & 0.007 & 0.279 & 0.355 \\
\hline Trust & 4.13 & 0.057 & & & & \\
\hline Acceptance & 4.36 & 0.022 & $\mathrm{t} 0-\mathrm{t} 2$ & 0.010 & 0.270 & 0.364 \\
\hline Caring for others & 4.72 & 0.699 & & & & \\
\hline Connectedness with nature & 4.99 & 0.406 & & & & \\
\hline Transcendent experiences & 3.16 & 0.031 & $\mathrm{t} 0-\mathrm{t} 2$ & 0.004 & 0.291 & 0.286 \\
\hline Spiritual activities & 3.49 & 0.004 & $\begin{array}{l}\mathrm{t} 0-\mathrm{t} 2 \\
\mathrm{t} 0-\mathrm{t} 3\end{array}$ & $\begin{array}{c}<0.001 \\
0.014\end{array}$ & $\begin{array}{l}0.327 \\
0.222\end{array}$ & $\begin{array}{l}0.326 \\
0.222\end{array}$ \\
\hline
\end{tabular}

\subsubsection{Psycho-Spiritual Wellbeing}

Concerning psycho-spiritual wellbeing, participants improved significantly in psychological wellbeing on the subscales purpose in life $(p=0.001)$ and self-acceptance $(p=0.002)$ immediately, and three months after the intervention. Participants reported significant improvement in spiritual wellbeing on the subscale inner strength $(p=0.002)$, and relationship with a higher power $(p=0.005)$, three months after the intervention. Treatment benefits were small $(B<0.5)$, and not clinically relevant $(b<0.5 ; 10 \%$ on a 5 -point scale). Participants did not report significant improvement on the subscales positive relations with others, autonomy, environmental mastery, and personal growth (all part of the dimension psychological wellbeing). See Table 7.

Table 7. Psycho-Spiritual Wellbeing (Dutch RYFF). ${ }^{1}{ }^{2}$.

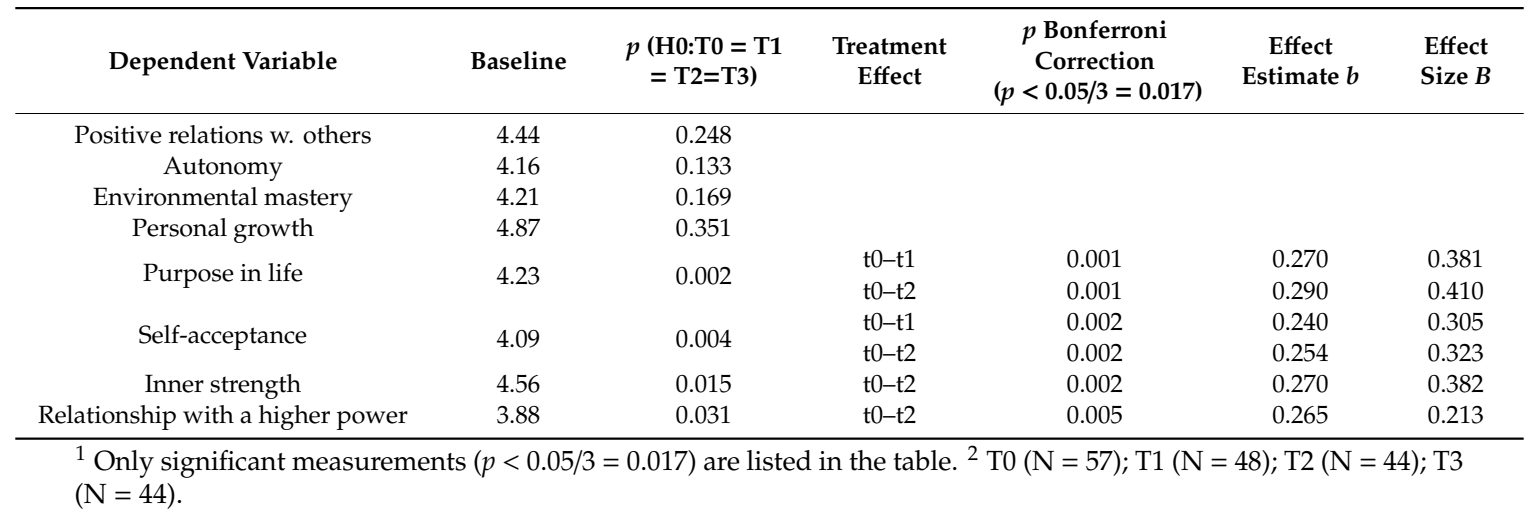

\subsubsection{Ego Integrity}

Concerning ego integrity, participants reported significantly more ego integrity (positive acceptance and fulfilment in life, in spite of negative experiences) immediately $(p<0.001)$, three months $(p<0.001)$, and nine months $(p<0.001)$ after the intervention. Treatment benefits were moderate $(0.5>B<0.8)$, and also clinically relevant immediately after the intervention $(b>0.5 ; 10 \%$ on a 5 -point scale). Participants reported, moreover, significantly less despair (regret about the life one has led, and feelings of sadness, failure and hopelessness) immediately $(p=0.002)$, and three months $(p<0.001)$ after the intervention. These treatment benefits were small $(B<0.5)$, and not clinically relevant $(b<0.5 ; 10 \%$ on a 5-point scale). See Table 8. 
Table 8. Ego-integrity (NEIS). ${ }^{1,2}$.

\begin{tabular}{|c|c|c|c|c|c|c|}
\hline Dependent Variable & Baseline & $\begin{array}{c}p(\mathrm{H} 0: \mathrm{T} 0=\mathrm{T} 1 \\
\quad=\mathrm{T} 2=\mathrm{T} 3)\end{array}$ & $\begin{array}{c}\text { Treatment } \\
\text { Effect }\end{array}$ & $\begin{array}{c}p \text { Bonferroni } \\
\text { Correction } \\
(p<0.05 / 3=0.017)\end{array}$ & $\begin{array}{c}\text { Effect } \\
\text { Estimate } b\end{array}$ & $\begin{array}{l}\text { Effect } \\
\text { Size } B\end{array}$ \\
\hline \multirow{3}{*}{ Ego integrity } & \multirow{3}{*}{4.19} & \multirow{3}{*}{$<0.001$} & $\mathrm{t} 0-\mathrm{t} 1$ & $<0.001$ & 0.481 & 0.606 \\
\hline & & & $\mathrm{t} 0-\mathrm{t} 2$ & $<0.001$ & 0.375 & 0.473 \\
\hline & & & $\mathrm{t} 0-\mathrm{t} 3$ & $<0.001$ & 0.434 & 0.547 \\
\hline \multirow{2}{*}{ Despair } & \multirow{2}{*}{3.15} & \multirow{2}{*}{0.001} & $\mathrm{t} 0-\mathrm{t} 1$ & 0.002 & -0.203 & -0.288 \\
\hline & & & $\mathrm{t} 0-\mathrm{t} 2$ & $<0.001$ & -0.247 & -0.352 \\
\hline
\end{tabular}

\section{Discussion}

This study provides evidence that SLR is likely to improve spiritual re-evaluation, spiritual growth, psycho-spiritual wellbeing, and ego integrity after the confrontation with cancer. The impact of SLR was explored by means of qualitative data collection and analysis concerning the impact of the intervention on spiritual re-evaluation and self-transcendence; and quantitative data collection and analysis concerning the impact of the intervention on spiritual growth, psycho-spiritual wellbeing, and ego integrity.

First, a model for understanding spiritual re-evaluation was developed. Cancer was conceptualized as a limit situation, as a radical disruption of life that not only urgently makes one aware of the limits to the self, but also ignites the human desire and ability to enhance life, and transcend the limits to concrete finite existence. Transcending the limits to the self was consequently considered as a dynamic process in which the expanding and crossing of the boundaries of existence can take place in different movements, directions, and dimensions. Based on Reed's, Frankl's and Tillich's conceptualization of transcending the limits to the self, spiritual re-evaluation was thereupon understood as the process in which one tries to overcome existential anxiety or despair over loss of the self by means of affirming the self. This anxiety over loss of the self was shown to take three different shapes: ontic anxiety concerning anxiety over fate and death; moral anxiety concerning anxiety over guilt, self-rejection and condemnation; and spiritual anxiety concerning anxiety over doubt and estrangement from one's ultimate concern. Finally, it was presumed that ontic, moral, and spiritual despair can be transcended by (1) taking a stand towards; (2) finding meaning in; and/or (3) accepting and embracing the self, 'in-spite-of' the circumstances and limits denying and negating the self of affirming itself.

Second, the impact of SLR on spiritual re-evaluation and self-transcendence was determined. It was found that in the confrontation with cancer, participants suffered primarily from ontic anxiety concerning fate and death. Participants tried to overcome this ontic anxiety first and foremost by finding meaning in their suffering, and by affirming life despite finitude, mortality, vulnerability, loss of control, and dependence. It was concluded that the confrontation with cancer primarily instigated a process in which participants seek to come to terms with their anxiety and uncertainty concerning their life, fate, and death, by affirming a meaningful present as opposed to an uncertain future, thus prompting a process of temporal transcendence. The intervention converted this process into a mainly moral re-evaluation, as the participants-after the intervention-acknowledged, affirmed, accepted and embraced themselves as themselves, asserting they may truly be who they are: "you are good the way you are". This acceptance and appreciation of themselves-as-themselves gained a spiritual undertow as the participants were more receptive to, and felt sustained by, the presence of an inner strength or depth, and of significant others; and felt an increased connectedness to themselves, and to others. The intervention thus transformed a process of ontic affirmation and temporal transcendence, into a process of moral and spiritual affirmation, leading to intra-, and interpersonal transcendence.

Finally, the impact of the intervention on spiritual growth and psycho-spiritual wellbeing was determined by means of a pre-post measurement for the effect of the intervention on spiritual growth, psycho-spiritual wellbeing, and ego integrity. It was found that the intervention improved the course of spiritual growth, consisting of connectedness with an inner strength (meaning, acceptance) and 
connectedness with the transcendent (spiritual activities, transcendent experiences); psychological wellbeing (consisting of purpose in life, self-acceptance); and spiritual wellbeing (consisting of inner strength, relationship with a higher power); and ego integrity (ego integrity vs. despair). Ego integrity seemed to be the most robust outcome of the intervention: statistically significant improvements in ego integrity occurred immediately, three months and nine months after the intervention. Improvements were moderate, and were clinically relevant. Psychological wellbeing improved, and despair reduced immediately, and three months after the intervention. Improvements were small, not clinically relevant, and no longer statistically significant nine months after the intervention. Improvements on spirituality, and spiritual wellbeing occurred three months after the intervention. Improvements were small, not clinically relevant, and no longer statistically significant nine months after the intervention. Improvements on spiritual activities remained statistically significant at nine months after the intervention.

The combined qualitative and quantitative findings of this study are summarized in Table 9. The combined results show the impact of cancer on the ontic domain, and the impact of the intervention on the moral, and the spiritual domain. See Table 9.

Table 9. Spiritual re-evaluation, spiritual growth, and psycho-spiritual wellbeing.

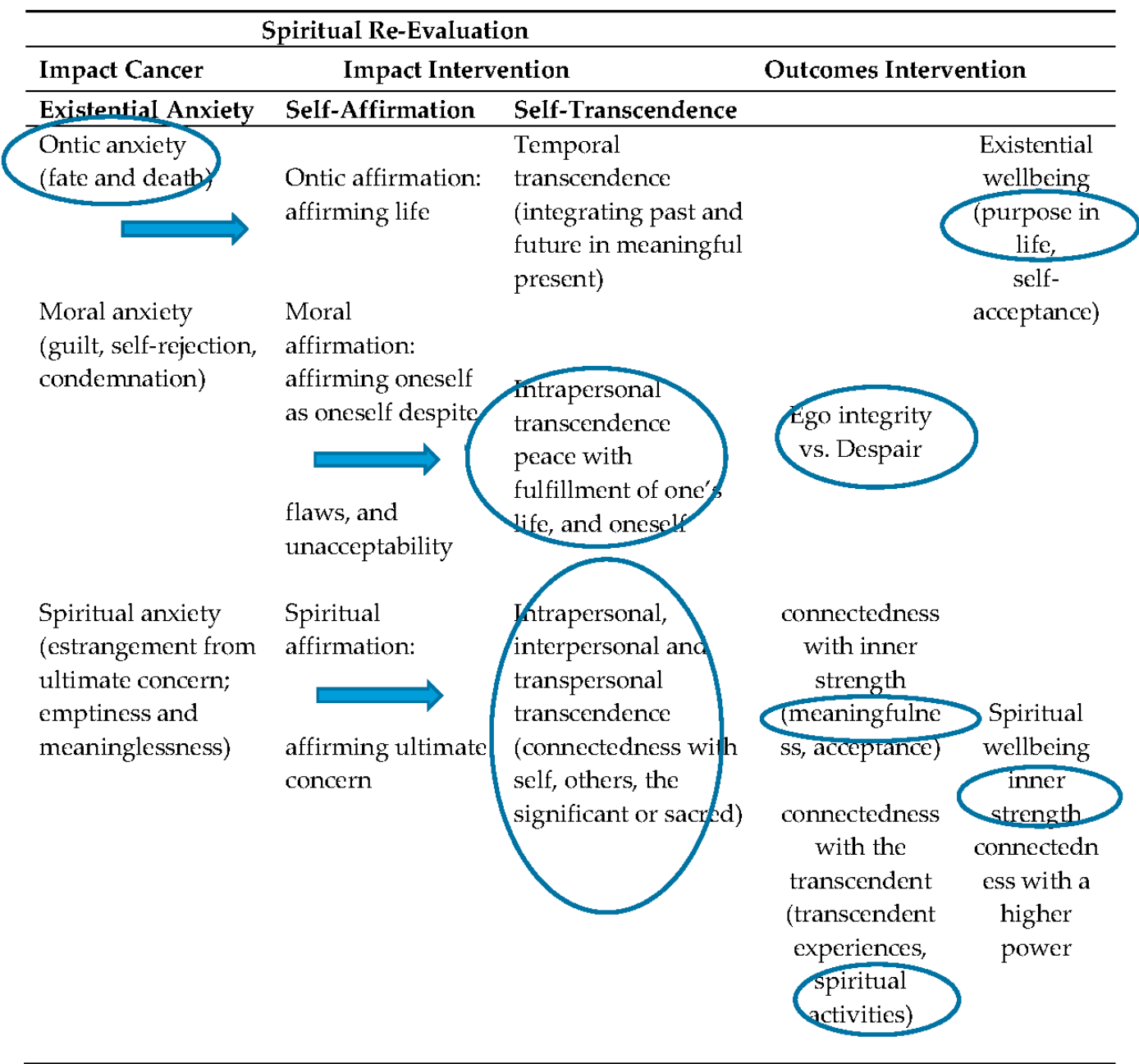

These findings are in line with the observations of Best et al. (2015), that transcendence of the suffering in cancer is attained by means of a spiritual re-evaluation, leading to spiritual growth, wellbeing, peace, and inner harmony (Best et al. 2015), or with more general observations that spiritual interventions may improve psycho-spiritual well-being (Bauereiß et al. 2018; Park et al. 2015; 
Xing et al. 2018). These findings are, moreover, in line with the results of previous studies on the effect of life review interventions on ego integrity (Kleijn et al. 2018; Pinquart and Simon 2012; Westerhof et al. 2010). These findings also support our expectation that a spiritual life review intervention may not only lead to ego integrity, but also to spiritual growth and psycho-spiritual wellbeing. More research is needed to gain a better understanding of this relationship.

In the introduction of this study, we argued that the confrontation with cancer leads to a confrontation with the limits to the self. Anxiety and despair over these limits can be transcended by a conscious outward search for meaning and transcendence, as Frankl would argue. Or by accepting and embracing the impossibility of overcoming existential suffering and despair, as Tillich would argue, and affirming the self by means of the 'courage to be'; a faith rooted in 'a power of being' that is greater than the power of oneself, or the power of one's world. The results of this study seem to suggest that the intervention transforms the spiritual re-evaluation in the context of cancer from a conscious search for transcendence of the self, into an affirmation of the self by means of a courage to be. Whereas before the intervention, people were aiming to transcend the limits to themselves by a search for the meaning of their suffering; the self-transcendence engendered by the intervention was more likely an affirmation based on a courage to be, as Tillich would understand it. Participants seemed to affirm the self 'in-spite-of' the circumstances and limits denying and negating them of affirming themselves. Participants accepted themselves as themselves, in spite of their flaws, and hidden and negative aspects of who they are. They felt sustained by a connectedness with an inner strength and with significant others. Based on these results, we cannot infer any conclusions on the character of this experience of 'feeling sustained'. More research is necessary as to whether this experienced sustenance by, and connectedness to, an inner strength or significant other, actually refers to a courage to be, a faith rooted in a power of being greater than the self or one's world, as Tillich intended.

The findings of this study indicate a different understanding of the distress caused by cancer, or of the best manner of addressing this distress. In the field of psycho-oncology, the confrontation with cancer is often understood as the existential plight or challenge of cancer, in which the occurrence of existential and spiritual distress initiates a cognitive search for meaning that might ultimately result in positive change, renewal or growth (Breitbart et al. 2010, 2015; Kissane 2012; Lee 2008; Pool 2009; Vehling and Kissane 2018; Weisman and Worden 1976). Such understanding of the challenge of cancer departs from the idea that existential or spiritual distress is grounded in the belief that one's life (in the face of cancer) is meaningless, and that existential distress can be addressed by incorporating the confrontation with cancer into a newly reconstituted meaning, that again provides a sense of order and purpose (Lee 2008); or by sustaining or enhancing one's sense of meaning (Breitbart et al. 2010, 2015, 2018). In order to understand how meaning can address distress, usually two different types of meaning are distinguished: global meaning and situational meaning (Park 2010, 2013). Global meaning refers to people's general orienting systems; to their beliefs, goals and sense of purpose; while situational meaning refers to meaning in a specific instance (Park 2010, 2013). The confrontation with cancer is understood to create a discrepancy between the appraised situational meaning of living with cancer, and one's global meaning. The search for meaning in this context is seen as the effort to reduce the discrepancy between the two types of meaning, either by searching for a more favorable understanding of the situation (the situational meaning), or by changing one's global meaning (Park 2013).

While the findings of this study support this understanding of the confrontation with cancer, it also suggests that the suffering in cancer affects more and different aspects of experience than the need for (cognitive) meaning and understanding alone. The impact of cancer in this study was shown to be first and foremost distress over limits to the self, such as fate and death; a distress that might be better addressed by a re-evaluation of oneself, one's life, and one's connectedness to the self, others, the significant, or sacred; than by a search for meaning alone.

This study provides evidence that a spiritual life review intervention actually impacts spiritual re-evaluation, spiritual growth, and psycho-spiritual wellbeing. To understand this impact better, 
it would be helpful to understand what narrative strategies facilitate spiritual re-evaluation; or whether different types of spirituality color the impact on spiritual re-evaluation differently.

\subsection{Limitations}

To our knowledge, this is the first mixed methods study to examine the impact of a spiritual life review intervention on spiritual re-evaluation, spiritual growth, and psycho-spiritual wellbeing. Our research is limited by its small study sample and the lack of a control group. The small study sample restricts generalizability of the findings of this study, and makes it impossible to differentiate the findings for demographic characteristics such as tumor types, or stages; the lack of a control group means that we cannot exclude the possibility that the improvements in spiritual re-evaluation, spiritual growth and psycho-spiritual wellbeing observed after the intervention, were due, in part, to other factors than study participation. That said, this is a mixed methods study, and the fact that the quantitative and qualitative results corroborate, supports the findings of this study, and puts these limitations in perspective. This study should be followed up with a randomized controlled trial to further evaluate the efficacy of a spiritual life review intervention, and with qualitative research to further explore the manner in which the intervention facilitates spiritual re-evaluation.

\subsection{Implications}

Despite the limitations, the results of this study suggest that people experiencing all-encompassing suffering in the context of cancer benefit from a spiritual life review intervention. Further development of, and research into, this type of intervention is therefore relevant, and necessary.

Author Contributions: Conceptualization, L.P., I.M.V.-d.L., and R.R.G. methodology, L.P., I.M.V.-d.L., and R.R.G.; validation, L.P., I.M.V.-d.L., and R.R.G.; formal analysis, L.P., and I.M.V.-d.L.; investigation, L.P.; data curation, L.P.; writing_original draft preparation, L.P.; writing—review and editing, L.P., I.M.V.-d.L., and R.R.G.; visualization, L.P.; supervision, I.M.V.-d.L., and R.R.G.; project administration, L.P.; funding acquisition, I.M.V.-d.L. All authors have read and agreed to the published version of the manuscript.

Funding: This research was funded by ADESSIUM FOUNDATION. The APC was funded by Amsterdam UMC.

Acknowledgments: The authors are thankful for Jannet Delver's role in developing the intervention, and initiating the research; Anke I. Liefbroer for her role in data analysis; and Birgit Witte, and Karen Holtmaat for their role in the statistical analysis.

Conflicts of Interest: The authors declare no conflict of interest. The funders had no role in the design of the study; in the collection, analyses, or interpretation of data; in the writing of the manuscript, or in the decision to publish the results. 


\section{Appendix A}

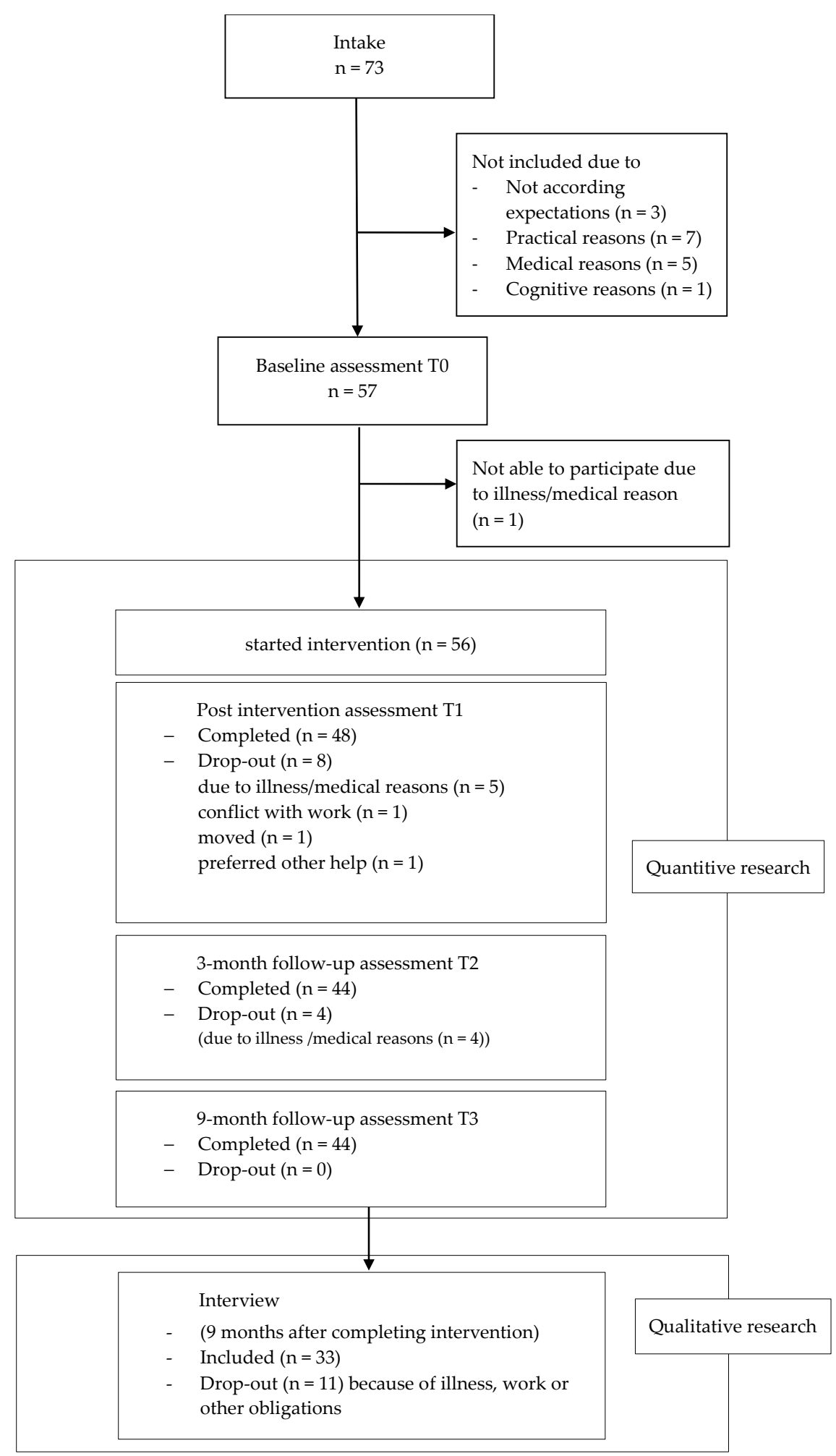

Figure A1. Flowchart. 


\section{Appendix B}

Table A1. Coding Scheme.

\begin{tabular}{|c|c|c|c|c|c|c|}
\hline \multirow[t]{2}{*}{ Resp. nr: } & \multicolumn{6}{|c|}{ Re-Evaluation } \\
\hline & Content & $\begin{array}{l}\text { Witness/Presence of } \\
\text { Respondents }\end{array}$ & $\begin{array}{c}\text { Witness/Presence of } \\
\text { (O)thers }\end{array}$ & $\begin{array}{c}\text { Finding } \\
\text { Meaning/Meaning } \\
\text { Making }\end{array}$ & Attitude & $\begin{array}{l}\text { Anxiety vs. } \\
\text { Affirmation }\end{array}$ \\
\hline & $\begin{array}{l}\text { What is of ultimate } \\
\text { concern? (self, other, } \\
\text { other meaning or } \\
\text { presence; lived } \\
\text { experience; practices) }\end{array}$ & $\begin{array}{l}\text { For whom is resp. } \\
\text { receptive/present; } \\
\text { whom does resp. } \\
\text { hear/see/acknowledge/ } \\
\text { sustain? }\end{array}$ & $\begin{array}{l}\text { Who is } \\
\text { receptive/present; By } \\
\text { whom is resp. } \\
\text { heard/seen/acknowledged/ } \\
\text { sustained? }\end{array}$ & $\begin{array}{l}\text { What meaning does } \\
\text { resp. find in suffering; } \\
\text { in life, in works, } \\
\text { creations; in } \\
\text { experiences, encounters }\end{array}$ & $\begin{array}{l}\text { Taking a stand to life, } \\
\text { conditions of life, illness; } \\
\text { fulfillment of self; } \\
\text { ultimate concern }\end{array}$ & $\begin{array}{l}\text { - ontic (fate/death) } \\
\text { - moral (guilt, } \\
\text { condemnation) } \\
\text { - spiritual (doubt, } \\
\text { estrangement) }\end{array}$ \\
\hline & in vivo & $\begin{array}{c}\text { self, other, other } \\
\text { meaning or presence }\end{array}$ & $\begin{array}{c}\text { self, other, other } \\
\text { meaning or presence }\end{array}$ & in vivo & in vivo & in vivo \\
\hline \multicolumn{7}{|l|}{ Before illness } \\
\hline \multicolumn{7}{|l|}{ Impact of illness } \\
\hline \multicolumn{7}{|l|}{ During intervention } \\
\hline \multicolumn{7}{|l|}{$\begin{array}{c}\text { Impact of } \\
\text { intervention }\end{array}$} \\
\hline $\begin{array}{c}\text { General } \\
\text { notes/observations }\end{array}$ & & & & & & \\
\hline
\end{tabular}




\section{References}

Anbeek, Christa. 2013. Aan De Heidenen Overgeleverd: Hoe Theologie De 21ste Eeuw Kan Overleven. Utrecht: Ten Have.

Bauereiß, Natalie, Stefanie Obermaier, Selcuk Erol Özünal, and Harald Baumeister. 2018. Effects of existential interventions on spiritual, psychological, and physical well-being in adult patients with cancer: Systematic review and meta-analysis of randomized controlled trials. Psychooncology 27: 2531-45. [CrossRef] [PubMed]

Best, Megan, Lynley Aldridge, Phyllis Butow, Ian Olver, and Fleur Webster. 2015. Conceptual analysis of suffering in cancer: A systematic review. Psychooncology 24: 977-86. [CrossRef] [PubMed]

Breitbart, William, Barry Rosenfeld, Christopher Gibson, Haley Pessin, Shannon Poppito, Christian Nelson, Alexis Tomarken, Anne Kosinski Timm, Amy Berg, Colleen Jacobsen, and et al. 2010. Meaning-Centered Group Psychotherapy for patients with advanced cancer: A pilot randomized controlled trial. Psycho-Oncology 19: 21-28. [CrossRef] [PubMed]

Breitbart, William, Barry Rosenfield, Haley Pessin, Alisson Applebaum, Julia Kulikowski, and Wendy G. Lichtental. 2015. Meaning-Centered Group Psychotherapy: An Effective Intervention for Improving Psychological Well-Being in Patients with Advanced Cancer. Journal of Clinical Oncology 33: 749-54. [CrossRef] [PubMed]

Breitbart, William, Haley Pessin, Barry Rosenfeld, Alisson J. Applebaum, Wendy G. Lichtental, Yuelin Li, Rebecca M. Saracino, Allison M. Marziliano, Melissa Masterson, Kristen Tobias, and et al. 2018. Individual meaning-centered psychotherapy for the treatment of psychological and existential distress: A randomized controlled trial in patients with advanced cancer. Cancer 124: 3231-39. [CrossRef] [PubMed]

Cohen, Jacob. 1977. Statistical Power Analysis for the behavioral Sciences. San Diego: Academic Press.

Coward, Doris D. 1991. Self-transcendence and emotional well-being in women with advanced breast cancer. Oncology Nursing Forum 18: 857-63. [PubMed]

Coward, Doris D. 2003. Facilitation of self-transcendence in a breast cancer support group: II. Oncology Nursing Forum 30: 291-300. [CrossRef]

Coward, Doris D., and Pamela G. Reed. 1996. Self-transcendence: A resource for healing at the end of life. Issues Ment Health Nursing 17: 275-88. [CrossRef]

Carel, Havi. 2016. Phenomenology of Illness. Oxford: Oxford University Press.

de Jager-Meezenbroek, Eltica, Machteld vd. Berg, Gerwi Tuytel, Adriaan Visser, and Bert Garssen. 2006. Het meten van spiritualiteit als een universeel fenomeen: De ontwikkeling van de Spirituele Attitude en Interesse Lijst (SAIL). Psychosociale Oncologie 14: 14-15.

de Jager Meezenbroek, Eltica, Bert Garssen, Machteld van den Berg, Gerwi Tuytel, Dirk van Dierendonck, Adriaan Visser, and Wilmar B. Schaufeli. 2012. Measuring spirituality as a universal human experience: Development of the Spiritual Attitude and Involvement List (SAIL). Journal of Psychosocial Oncology 30: 141-67. [CrossRef]

Frankl, Viktor E. 1955. The Doctor and the Soul. New York: Knopf.

Frankl, Viktor E. 1988. The Will to Meaning: Foundations and Applications of Logotherapy. New York: Penguin.

Frank, Arthur W. 1991. The Wounded Storyteller. Chicago: University of Chicago Press.

Frank, Arthur W. 1998. Stories of illness as care of the self: A Foucauldian dialogue. Health 2: 329-48. [CrossRef]

Ganzevoort, R. Ruard. 2001. Chronische aandoeningen en zingeving. TvZ. Tijdschift voor Verpleegkundigen 18/111: 686-89.

Ganzevoort, R. Ruard. 2006. The social construction of revelation. International Journal of Practical Theology 8: 1-14. [CrossRef]

Ganzevoort, R. Ruard, and Jan Visser. 2007. Zorg voor Het Verhaal. Achtergronden, Methode en Inhoud van Pastorale Zorg. Zoetermeer: Meinema.

Hill, Peter C., Kenneth I. Pargament, Ralph W. Hood Jr., Michael E. McCullough, James P. Swyers, David B. Larson, and Brian J. Zinnbauer. 2000. Conceptualizing religion and spirituality: Points of commonality, points of departure. Journal for the Theory of Social Behaviour 30: 51-77. [CrossRef]

Hefferon, Kate, Madeleine Grealy, and Nanette Mutrie. 2009. Post-traumatic growth and life threatening physical illness: A systematic review of the qualitative literature. British Journal of Health Psychology 14: 343-78. [CrossRef]

Jaspers, Karl. 1919. Psychologie der Weltanschauungen. Berlijn: Springer.

Jaspers, Karl. 1938. Existenzphilosophie. Drei Vorlesungen. Berlijn: Springer. 
Jaspers, Karl. 1951. Inleiding tot De philosophie. Assen: Born.

Jeong, HyeSun, and HyunSoo Oh. 2015. Evaluating the Compehensive Model of Ego Integrity for Senior Patients in Convalescent Hospitals: Influence Factors and Outcome Variables. International Journal of Bioscience and Bio-Technology 7: 317-26. [CrossRef]

Kissane, David W. 2012. The relief of existential suffering. Archives of Internal Medicine 172: 1501-5. [CrossRef] Kleijn, Gitta, Lenneke Post, Birgit I. Witte, Ernst T. Bohlmeijer, Gerben J. Westerhof, Pim Cuijpers, and Irma I. Verdonck-de Leeuw. 2016. Psychometric Characteristics of a Patient Reported Outcome Measure on Ego-Integrity and Despair among Cancer Patients. PLoS ONE 11: e0156003. [CrossRef]

Kleijn, Gitta, Birgit I. Lissenberg-Witte, Ernst T. Bohlmeijer, Bas Steunenberg, Kitty Knipscheer-Kuijpers, Vincent Willemsen, Annemarie Becker, Egbert F. Smit, Corien M. Eeltink, Anna M. E. Bruijnzeel, and et al. 2018. The efficacy of Life Review Therapy combined with Memory Specificity Training (LRT-MST) targeting cancer patients in palliative care: A randomized controlled trial. PLoS ONE 13: e0197277. [CrossRef]

Lee, Virginia. 2008. The existential plight of cancer: Meaning making as a concrete approach to the intangible search for meaning. Support Care Cancer 16: 779-85. [CrossRef]

Maslow, Abraham. H. 1971. The Farther Reaches of Human Nature. New York: Penguin.

McAdams, Dan P. 1996. Personality, Modernity, and the Storied Self: A Contemporary Framework for Studying Persons. Psychological Inquiry 5: 295-321. [CrossRef]

McAdams, Dan P. 2001. The psychology of life stories. Review of General Psychology 5: 100-22. [CrossRef]

McAdams, Dan P. 2009. The Person: An Introduction to the Science of Personality Psychology, 5th ed. New York: Wiley.

Oh, Pok-Ja, and Soo H. Kim. 2014. The effects of spiritual interventions in patients with cancer: A meta-analysis. Oncology Nursing Forum 41: E290-E301. [CrossRef] [PubMed]

Pargament, Kenneth I. 1997. The Psychology of Religion and Coping; Theory, Research, Practice. New York: Guildford.

Pargament, Kenneth I. 2013. Spirituality as an Irreducible Human Motivation and Process. International Journal for the Psychology of Religion 23: 271-81. [CrossRef]

Park, Crystal L. 2010. Making sense of the meaning literature: An integrative review of meaning making and its effects on adjustment to stressful life events. Psychol. Bull. 136: 257-301. [CrossRef]

Park, Crystal L. 2013. Spirituality and meaning making in cancer survivorship. In The Psychology of Meaning. Edited by Keith D. Markman, Travis Proulx and Matthew J. Lindberg. Washington, DC: American Psychological Association, pp. 257-77.

Park, Crystal L, Sherman Allen C., Heather S. L. Jim, and John M. Salsman. 2015. Religion/spirituality and health in the context of cancer: Cross-domain integration, unresolved issues, and future directions. Cancer 121: 3789-94. [CrossRef]

Pinquart, Martin, and Forstmeier Simon. 2012. Effects of reminiscence interventions on psychosocial outcomes: A meta-analysis. Aging Ment Health 16: 541-58. [CrossRef]

Pool, Grieteke. 2009. Kanker: Een existentiële opgave. In Psychologische Patiëntenzorg in de Oncologie. Edited by Hanneke deHaes, Leo G. van Wezel and Robbert Sanderman. Assen: van Gorcum, pp. 134-52.

Puchalski, Christina, Betty Ferrell, Rose Virani, Shirley Otis-Green, Pamela Baird, Janet Bull, Harvey Chochinov, George Handzo, Holly Nelson-Becker, Maryo Prince-Paul, and et al. 2009. Improving the quality of spiritual care as a dimension of palliative care: The report of the Consensus Conference. J. Palliat. Med. 12: 885-904. [CrossRef]

Puchalski, Christina M., Robert Vitillo, Sharon K. Hull, and Nancy Reller. 2014. Improving the Spiritual Dimension of Whole Person Care: Reaching National and International Consensus. J. Palliat. Med. 17: 642-656. [CrossRef]

Ricœur, Paul. 1984. Time and Narrative. Chicago: University of Chicago Press, Volume 3.

Ricœur, Paul. 1991. From Text to Action, Essays in Hermeneutics. Evanston: Northwestern University Press.

Ricœur, Paul. 1992. Oneself as Another. Chicago: University of Chicago Press.

Reed, Pamela. G. 2009. Demystifying self-transcendence for mental health nursing practice and research. Archives of Psychiatric Nursing 23: 397-400. [CrossRef]

Staude, John-Raphael. 2005. Autobiography as a spiritual practice. Journal of Gerontological Social Work 45: 249-69. [CrossRef]

Taylor, Charles. 2007. A Secular Age. Cambridge: Belknap Press of Harvard University Press.

ter Borg, Meerten. 2010. Vrijzinnigen Hebben de Toekomst. Zoetermeer: Meinema. 
Thomas, Jeani C., Mattie Burton, Mary T. Quin Griffin, and Joyce J. Fitzpatrick. 2010. Self-transcendence, spiritual well-being, and spiritual practices of women with breast cancer. Journal of Holistic Nursing 28: 115-22. [CrossRef] [PubMed]

Tillich, Paul. 2000. The Courage to be. New Haven: Yale University Press. First published 1952.

Tillich, Paul. 1956. Dynamics of Faith. New York: Harper.

van Dierendonck, Dirk. 2004. The construct validity of Ryff's Scales of Psychological Well- being and its extension with spiritual well-being. Personality and Individual Differences 36: 629-43. [CrossRef]

van den Brink, Gabriel. 2012. De Lagere Landen en het Hogere. De betekenis van Geestelijke Beginselen in Het Moderne Bestaan. Amsterdam: Amsterdam University Press.

Visser, Anja, Nicoline Uwland, and Bert Garssen. 2013. De rol van spiritualiteit bij het omgaan met kanker: Gemengde-methodenstudie. Psyche E Geloof 24: 171-83.

Vehling, Sigrun, and David W. Kissane. 2018. Existential distress in cancer: Alleviating suffering from fundamental loss and change. Psychooncology 27: 2525-30. [CrossRef] [PubMed]

Waaijman, Kees. 2000. Spiritualiteit: Vormen, Grondslagen, Methoden. Gent: Carmelitana.

Wakefield, Dan. 1990. The Story of your life. In Writing a Spiritual Autobiography. A Step to Step Approach to Exploring Your Past and Understanding Your Present. Boston: Beacon Press.

Weisman, Avery D., and J. William Worden. 1976. The existential plight in cancer: Significance of the first 100 days. The International Journal of Psychiatry in Medicine 7: 1-15. [CrossRef]

Westerhof, Gerben J., Ernst Bohlmeijer, and Jeffrey D. Webster. 2010. Reminiscence and mental health: A review of recent progress in theory, research and interventions. Ageing E Society 30: 697-721. [CrossRef]

Westerhof, Gerben J., and Ernst T. Bohlmeijer. 2014. Celebrating fifty years of research and applications in reminiscence and life review: State of the art and new directions. The Journal of Aging Studies 29: 107-114. [CrossRef]

Weathers, Elizabeth, Geraldine McCarthy, and Alice Coffey. 2016. Concept Analysis of Spirituality: An Evolutionary Approach. Nursing Forum 51: 79-96. [CrossRef]

Xing, Lu, Xiujing Guo, Lu Bai, Jiahui Qian, and Jing Chen. 2018. Are spiritual interventions beneficial to patients with cancer? A meta-analysis of randomized controlled trials following PRISMA. Medicine (Baltimore) 97: e11948. [CrossRef]

Yalom, Irvin D. 2008. Staring at the Sun. Overcoming the Dread of Death. London: Piatkus.

(C) 2020 by the authors. Licensee MDPI, Basel, Switzerland. This article is an open access article distributed under the terms and conditions of the Creative Commons Attribution (CC BY) license (http://creativecommons.org/licenses/by/4.0/). 